\title{
“Amutuy, soledad": um estudo das estratégias identitárias na canção de Marcel Berbel
}

\author{
“Amutuy, soledad”: un estudio de las estrategias identitarias en la \\ canción de Marcel Berbel \\ "Amutuy, soledad": a study of the identity strategies in the song of Marcel
} Berbel

Nathan Bastos de Souza ${ }^{1}$

\begin{abstract}
Resumo
O objetivo deste texto é analisar o discurso identitário da canção "Amutuy, soledad", letra de Marcel Berbel, que constitui uma forte relação com o folclore argentino. A canção é seccionada em três elementos que compõem o gênero discursivo: forma, estilo e tema. O último é o objeto de estudos aqui, sob o qual se incidirá a análise amparada metodologicamente no paradigma indiciário (GINZBURG, 1989). A discussão teórica avança para além das fronteiras da linguística, portanto, além de teóricos da linguagem (VOLOSHINOV/BAKHTIN, 1976; BAKHTIN, 1997; BAKHTIN, 2011), trabalhamos com estudiosos da cultura (HALL, 2011), da sociologia (BAUMAN, 2005; CANCLINI, 2008) e da história (DUARTE; GONZALEZ, 2012). Os resultados apontam para os mitos fundacionais do povo latinoamericano, relacionando três tempos cíclicos: o primeiro é o tempo da conquista/invasão da América Latina, o segundo, tempo da "Campanha do deserto" e, por fim, o tempo presente, das comemorações dos 500 anos da chegada dos europeus. As considerações finais estabelecem uma analogia entre as relações líquidas que vivemos hoje em dia e as questões da identidade $\mathrm{x}$ alteridade.
\end{abstract}

Palavras-chave: tempo grande; discurso identitário; (pós)modernidade (líquida); mitos fundacionais.

\section{Resumen}

El objetivo de este texto es analizar el discurso identitário de la canción "Amutuy, soledad", letra de Marcel Berbel, que constituye una fuerte relación con el folclore argentino. La canción es seccionada en tres elementos que componen el género discursivo: forma, estilo y tema. El último es el objeto de estudios acá, en el cuál se incidirá un análisis amparada metodológicamente en el paradigma indiciario (GINZBURG, 1989). La discusión teórica avanza para más allá de las fronteras de la lingüística, por lo tanto, más allá de los teóricos del lenguaje (VOLOSHINOV/BAKHTIN, 1976; BAKHTIN, 1997; BAKHTIN, 2011), trabajamos con los expertos en la cultura (HALL, 2011), de la sociología (BAUMAN, 2005; CANCLINI, 2008) y de la historia (DUARTE; GONZALEZ, 2012). Los resultados apuntan hacia los mitos fundacionales del pueblo latinoamericano, relacionando tres tiempos cíclicos: el primero es el tiempo de la conquista/invasión de Latinoamérica, el segundo, es el tiempo de "Campaña del desierto" y, por último, el tiempo presente, de la conmemoraciones de los 500 años de la llegada de los europeos. Las consideraciones finales establecen una analogía entre las relaciones líquidas que vivimos hoy día y las cuestiones de la identidad $\mathrm{X}$ alteridad.

Palabras claves: tiempo grande; discurso identitário; (pos) modernidad (líquida); mitos fundacionales.

\footnotetext{
${ }^{1}$ Doutorando em Linguística pelo Programa de Pós-graduação em Linguística da Universidade Federal de São Carlos (PPGL/UFSCar). Graduado em Letras Espanhol e Português pela Universidade Federal do Pampa (UNIPAMPA) e Mestre em Linguística pela UFSCar. É membro do Grupo de Estudos Bakhtinianos do Pampa (GEBAP/UNIPAMPA) e do Grupo de estudos dos Gêneros do Discurso (GEGe/UFSCar). O presente trabalho foi realizado com apoio da Coordenação de Aperfeiçoamento de Pessoal de Nível Superior - Brasil (CAPES) - Código de Financiamento 001. nathanbastos600@ gmail.com.
} 


\begin{abstract}
The aim of this paper is to analyze the identity discourse of the song "Amutuy, soledad", Marcel Berbel letter, which constitutes a strong relationship with Argentine folklore. The song is sectioned into three elements that make up the discourse genre: fashion, style and theme. The latter is the object of study here, under which it focus methodologically supported in the evidential paradigm (GINZBURG, 1989) analysis. The theoretical discussion goes beyond the boundaries of linguistic isolation, so in addition to theoretical language (VOLOSHINOV/BAKHTIN, 1976; BAKHTIN, 1997; BAKHTIN, 2011), working with scholars of culture (HALL, 2011), sociology (BAUMAN, 2005; CANCLINI, 2008) and history (DUARTE; GONZALEZ, 2012). The results point to the foundational myths of the Latin American people, linking three cycle times: the first is the time of the conquest/invasion of Latin America, the second time the "Campaign of the Desert" and finally, this time, the celebrations of 500 years of the arrival of Europeans. The final considerations establish an analogy between the net relationships we live today and the questions of identity $\mathrm{x}$ otherness.
\end{abstract}

Keywords: big time; identity discourse; (post) modernity (net); foundational myths.

[...] no Tempo Grande nada desaparece sem deixar sinal, tudo renasce para uma nova vida. Com a nova época tudo o que aconteceu antes e que a humanidade viveu soma-se e enche-se de um novo sentido.

Mikhail BAKHTIN

\title{
Primeiras palavras
}

Geraldi (2015) afirma que os estudos da linguagem na contemporaneidade têm de ser mais voltados às relações com outras áreas de saber, especialmente, com as humanidades. Saussure, o pai da linguística, e seu método de "recorte linguístico", é o principal inspirador de um método científico rigoroso para estudar a linguagem. A partir do autor, os linguistas estruturalistas aprenderam a segmentar a língua, em unidades cada vez menores para descobrir a verdade por trás ou através delas. A linguística de Saussure (2012) teve de buscar rigorosidade no exterior das humanidades, para tanto, encontrou os métodos da matemática e das ciências duras.

$\mathrm{Na}$ atualidade, no entanto, estamos procurando estabelecer outros contatos, com as disciplinas das ciências humanas, que são, por assim dizer, mais próximas dos estudos da linguagem. O início desse diálogo culminou com o fim da utopia da objetividade e da cientificidade nas ciências humanas, assim, "chegamos a estes tempos carregados de contrapalavras - aquelas que a pesquisa objetiva conseguiu produzir e aquelas com que queremos recensear noções para construir compreensões.” (GERALDI, 2015, p. 52). E essas contrapalavras que viemos carregados nos fazem, obrigatoriamente, pensar em uma metodologia para a pesquisa em ciências humanas, uma ciência outra, uma "metalinguagem de todas as ciências", "uma hetorociência" (BAKHTIN, 2011), que já "não caiba mais nos tubos de ensaio" (SOUZA, 2016). 
A respeito dos "gêneros do discurso", Bakhtin (2011) afirma que, por mais variadas que sejam as esferas da atividade humana, elas estão, impreterivelmente, atreladas à utilização da língua. Dessa maneira, não é estranho dizer que os modos dessa utilização sejam, igualmente, tão variados. A utilização da língua se dá por meio de enunciados, que podem ser orais ou escritos, provindos de sujeitos em uma ou outra esfera da atividade humana. Esses enunciados, Bakhtin (2011) denomina gêneros do discurso, definindo-os como tipos "relativamente estáveis de enunciados" e que obedecem a três elementos constituidores: o “[...] conteúdo temático, o estilo e a construção composicional [...]” (p. 262).

Para sermos mais específicos, no contexto deste artigo, estudamos o discurso de identidade na canção "Amutuy, soledad"2, letra de Marcel Berbel (1925 - 2003) - escritor e poeta argentino - que em 1998 foi gravada por Ruben Patagonia, mas obteve sucesso na voz de Soledad Pastorutti no Festival Nacional de Folclore de Cosquín (DUARTE; GONZALEZ, 2012). A característica do gênero discursivo com a qual trabalharemos é o tema ${ }^{3}$. O artigo, além disso, se inscreve numa linha de esforços para lidar com questões relativas à América Latina (SOUZA, 2014) e ao cancioneiro folclórico de Soledad Pastorutti (SOUZA, 2017). O objetivo deste artigo é investigar qual(is) sentido(s) faz(em) com que o discurso de uma canção contemporânea seja tão relacionado com o conceito de identidade, fortemente demarcado, e fechado em si mesmo ${ }^{4}$.

Este artigo está organizado da seguinte maneira: a próxima seção é o espaço em que se discutem as teorias envolvidas que, por sua vez, avançam para além das fronteiras da linguística, portanto, ademais de teóricos da linguagem (VOLOSHINOV/BAKHTIN, 1976; BAKHTIN, 1997; BAKHTIN, 2011), trabalhamos com estudiosos da cultura (HALL, 2011), da sociologia (BAUMAN, 2005; CANCLINI, 2008) e da história (DUARTE; GONZALEZ, 2012). No arcabouço teórico, revisamos o conceito de identidade na pós-modernidade ou na era líquida e o cotejamos com as alteridades constitutivas dos sujeitos contemporâneos. $\mathrm{O}$ paradigma indiciário é o percurso metodológico escolhido e explicitado na seção 2. Posteriormente, apresentamos a análise da canção a partir dos indícios levantados. Por fim, as considerações finais, que dão um fecho ao trabalho, seguidas das referências bibliográficas.

\footnotetext{
${ }^{2}$ As passagens da canção constantes neste trabalho estarão na língua espanhola; preferiu-se não fazer a tradução. ${ }^{3}$ Dado o limite de páginas deste texto, foi feito um recorte no objeto que nos possibilite desenvolver alguma reflexão. Para um aprofundamento sobre o tema do folclore argentino em contexto, consultar Souza (2017).

${ }^{4}$ Já que, como afirma Ponzio (2012), a identidade é uma armadilha e precisamos alargar a compreensão da palavra na relação com a alteridade.
} 
RELACult - Revista Latino-Americana de Estudos em Cultura e Sociedade

\section{A identidade na pós-modernidade ou na era líquida e as alteridades constitutivas dos sujeitos contemporâneos}

De início, é imprescindível a questão intrínseca do gênero, visto que se trata do modo como a história da sociedade influencia na história da língua ou de como os sujeitos interagem em contextos específicos de interlocução. Quando trabalhamos com canções folclóricas, temos de reconhecer esse potencial de apontar para as questões de identidade que elas possivelmente venham a veicular, já que o termo folclore remete aos conhecimentos acumulados pelos povos (BRANDÃO, 1984; CHULLIVER, 2012). Uma forma de tradição, transmitida oralmente ou de forma escrita, que com maior ou menor grau dá indícios de "[uma] visão de mundo de uma classe social, de um escritor, ou de toda uma sociedade" (GINZBURG, 1989). Em outras palavras, as mentalidades de uma época, de um escritor, de um cantor, dos sujeitos ouvintes estão representadas pelos versos.

Tomamos de empréstimo o conceito de "artístico" de Voloshinov/Bakhtin (1976) para discutirmos o modo como incidiremos nosso olhar sobre a canção:

[...] o 'artístico' na sua total integridade não se localiza nem no artefato nem nas psiques do criador e do contemplador consideradas separadamente; ele contém todos os três fatores. $\mathrm{O}$ artístico é forma especial de interrelação entre criador e contemplador fixada em uma obra de arte (VOLOSHINOV/BAKHTIN, 1976, p. 3).

Assim, a canção - que antes de ser gravada era poesia - será tratada com aspecto de obra de arte. Procuraremos entender como, do ponto de vista da contemplação, esse discurso identitário significa na canção. Em outras palavras, o artefato canção, por si só, não possui toda a significação. É necessária essa relação dialógica entre o contemplador e o criador para que o discurso presente faça sentido na relação de interlocução estabelecida. A obra de arte é o espaço do dialogismo: do tratamento das relações interativas entre obra, contemplador e autor, os três polos fundamentais para que seja considerada como arte. Bakhtin (2009) afirma que nos limites da língua o sentido não se instala, portanto, é preciso uma relação entre o que é de ordem linguística e o que é da ordem histórica, contextual.

Para nosso objeto estético, a canção, e as relações que estabelecemos dele com o contexto, duas noções advindas da teoria bakhtiniana nos ajudam: o tempo pequeno e tempo grande. O tempo pequeno é entendido por Mello e Miotello nos seguintes termos:

O tempo pequeno é o tempo do aqui e do agora, tempo da vida, tempo da ética, quando estou completamente relacionado com minha realidade presente de vida. É um tempo no qual vivo enquanto eu-mesmo-para-mim. É o tempo da completude, 
quando me monologizo e me completo. Tempo absolutamente necessário. Preciso estabelecer por completo meus limites diante do outro-para-mim (MELLO; MIOTELLO, 2013, p. 223).

Dessa maneira, o tempo pequeno, lugar em que nos monologizamos, que vivemos para nós mesmos, é o lugar da identidade. Mas, o mundo atual exige-nos viver para a alteridade (MIOTELLO; MOURA, 2012; MELLO; MIOTELLO, 2013). Este tempo para viver para si mesmo é necessário, absolutamente. Contudo, o tempo grande, o tempo do viver para a alteridade, é aquele em que nada some sem deixar sinal. Aqui todos os acontecimentos renascem para uma nova vida, regada de passado, cheia de novos sentidos, adquiridos nas interações do hoje com o ontem. Nesse grande tempo, as palavras ganham sentido porque apontam-nos a uma memória do passado que tem, por sua vez, uma memória de futuro, direcionando o dizer sempre para o futuro com base no já vivido.

Para inferir sobre o potencial do discurso presente na canção, devemos recorrer às questões da identidade. Bauman (2005, p. 33) afirma que "no admirável mundo novo das oportunidades fugazes e das seguranças frágeis, as identidades ao estilo antigo, rígidas e inegociáveis, simplesmente não funcionam". Conforme experimentamos viver contemporaneamente, no mundo em que as relações estão liquefeitas as identidades ao modo antigo, como experimentadas na modernidade, não poderiam sobreviver. A própria concepção de identidade é problemática, já que presenciamos a todo o momento os pontos de ancoragem dos indivíduos se desfazendo. Para Bauman (2005), a ideia de identidade surgiu de uma crise do pertencimento.

Hall (2011) lembra que as chamadas "velhas identidades" - em declínio - estão descentrando os sujeitos daqueles papéis que ocupavam no mundo. $\mathrm{O}$ que tem gerado o que chamamos de "crise de identidade". Hall (2011) afirma que há uma relação do deslizamento das identidades com a questão dos mercados:

\footnotetext{
Quanto mais a vida social se torna mediada pelo mercado global de estilos, lugares e imagens, pelas viagens internacionais, pelas imagens da mídia e pelos sistemas de comunicação globalmente interligados, mais as identidades se tornam desvinculadas - desalojadas - de tempos, lugares, histórias e tradições específicos e parecem 'flutuar livremente'. (grifo nosso) (HALL, 2011, p. 75).
}

O "flutuar livremente" parece ser causado pelo desenvolvimento econômico gerado pela globalização ou pela imaginação dela, como afirma Canclini (2008). Já que, para o autor argentino, há somente duas possibilidades, "globalizarnos o defender la identidad" (CANCLINI, 2008, p.21). Nesse aspecto faz sentido problematizar as identidades nacionais, 
tais como enfrentamos no mundo atual. Hall (2011) defende a posição de que as identidades, a partir da mediação dos mercados, começaram a se desfazer; de que a globalização é um agravante para as crises de identidade que presenciamos no mundo de hoje.

De acordo com Hall (2011), as identidades nacionais não são adquiridas de nascimento, e sim formadas no interior da representação da ideia de nação. Para Bauman (2005), as identidades nacionais nunca foram como as outras identidades; visto que nunca encontraram competição: através do Estado e das relações de poder, construiu-se um monopólio sob o qual se mirava aos lados e podia-se definir uma fronteira entre "nós" (identidade) e "eles" (diferença) ${ }^{5}$. É nesse sentido que Santos (2009) afirma existir um pensamento abissal, que entende o mundo como uma binariedade, em que para atentar a uma região a outra precisa ser paulatinamente apagada, tornada menos visível, esquecida. Por fim, segundo Bauman (2005), no líquido mundo moderno, as identidades estão em movimento: há grupos identitários, mas os agrupamentos são móveis e velozes. Constrói-se, então, uma identidade passageira de grupo, mantida viva, mas por pouco tempo (BAUMAN, 2005, p.32). O sociólogo polonês explica o crescimento de grupos identitários velozes pelo aparecimento de "comunidades guarda-roupa", invocadas a existirem:

[...] ainda que apenas na aparência, por pendurarem os problemas individuais, como fazem os frequentadores de teatros, numa sala. Qualquer evento espetacular ou escandaloso pode se tornar um pretexto para fazê-lo: um novo inimigo público elevado à posição de número 1; uma empolgante partida de futebol; um crime particularmente 'fotogênico', inteligente ou cruel; a primeira seção de um filme altamente badalado; ou o casamento, divórcio ou infortúnio de uma celebridade atualmente em evidência. As comunidades guarda-roupa são reunidas enquanto dura o espetáculo e prontamente desfeitas quando os espectadores apanham os seus casacos nos cabides. Suas vantagens em relação à 'coisa genuína' são precisamente a curta duração de seu ciclo de vida e a precariedade do compromisso necessário para ingressar nelas e (embora por breve tempo) aproveitá-las. Mas elas diferem da sonhada comunidade calorosa e solidária da mesma forma que as cópias em massa vendidas nas lojas de departamentos diferem dos originais produzidos pela alta costura... (BAUMAN, 2005, p. 37).

Assim, os grupos identitários na era líquida são transformados em comunidades em que se penduram os problemas individuais. Nesse sentido, parece ser possível afirmar que não existe mais o sentido de colaboração, de sociedades igualitárias. No mundo líquido o "eu" parece ter tomado o controle, as rédeas da situação. Assim, os grupos de indivíduos se liquefizeram, a sociedade que presenciamos hoje está pronta para formar grupos líquidos, que se desfazem com o simples término dos espetáculos. Os grupos atuais de indivíduos, que se constituem ao redor dos eventos espetaculares, são muito voltados para o pequeno tempo,

\footnotetext{
${ }^{5}$ Já que a diferença identifica: diz o que é "eu” e o que é "outro" (GERALDI, 2003).
} 
para o tempo curto. Para o tempo grande não existem mais grupos com identidades sólidas constituídas, já que o mundo está liquefeito nestes tempos de "modernidade líquida" (BAUMAN, 2001).

Nesse sentido, a qualidade dos grupos diminuiu, como explica Bauman (2005), o que acarreta que os sujeitos da era líquida busquem na quantidade a redenção. Pois, afirma o autor: "Se os compromissos, incluindo aqueles em relação a uma identidade particular, são 'insignificantes'[...], você tende a trocar uma identidade, escolhida de uma vez para sempre, por uma 'rede de conexões"”. (BAUMAN, 2005, p. 37). Essa rede de conexões que substitui uma identidade particular estabelece o que chamamos de identidade liquefeita, de um sujeito que está se constituindo no mundo contemporâneo e que vive nele as relações com os outros.

\section{Do percurso metodológico}

O paradigma indiciário é um modelo epistemológico que surge nas ciências humanas como metodologia de estudos científicos na reflexão de C. Ginzburg (1989). Primeiramente, singulariza-se o objeto de pesquisa, e constrói-se, então, um caminho interpretativo a partir dos dados coletados. O método, no entanto, não é uma descoberta recente. Segundo esse autor, a análise dos indícios revive os princípios da atividade humana que esteve presente nas primeiras sociedades de caçadores, os únicos capazes de partir de uma pista silenciosa deixada pela presa para compreender uma série lógica de eventos. Foi contemporâneo do homem que acreditava no contato com as divindades através de mensagens escritas que teriam de ser decifradas por adivinhos. A medicina é outra ciência que bebe nessa fonte do conhecimento indiciário (GIOVANI; SOUZA, 2014).

Trabalhar com a linguagem, que não é transparente, implica reconhecer que não podemos retirar do objeto a sua singularidade identificadora, mas, a partir das pistas encontradas, estabelecer relações e construir uma compreensão que explique o fenômeno em estudo, pois, "quando as causas não são reproduzíveis, só resta inferi-las a partir dos efeitos." (GINZBURG, 1989, p. 169). Para os estudos discursivos, a linguagem sendo opaca apresenta zonas privilegiadas - sinais, indícios - que permitem decifrá-la e é, a partir deste trabalho de detetive, que na subseção a seguir, buscaremos uma compreensão do discurso identitário veiculado pela canção. 
RELACult - Revista Latino-Americana de Estudos em Cultura e Sociedade

Revista Latinoamericana de Estudios en Cultura y Sociedad | Latin American Journal of Studies in Culture and Society V. 04, nº 02, mai-ago., 2018, artigo n ${ }^{\circ} 924$ | relacult.claec.org | e-ISSN: 2525-7870

\section{Os indícios recolhidos e a construção de uma compreensão}

A canção "Amutuy, soledad” é a que se apresenta a seguir:

“Ahí están festejando la conquista de ayer con mi propia bandera me robaron la fe

Los del Remintóng ${ }^{6}$ antes y sus leyes después. Pisotearon mis credos y mi forma de ser me impusieron cultura y este idioma también lo que no me impusieron fue el color de la piel.

Amutuy, Soledad, que mi hermano me arrincona, sin piedad vámonos que el hambre $y$ el fiscal pueden más, Amutuy, sin mendigar.

Ahí están festejando los del sable y la cruz como me despojaron sin ninguna razón sometiendo a mi raza en el nombre de Dios.

Con qué ley me juzgaron por culpable de qué de ser libre en mi tierra o ser indio tal vez, qué conquista festejan que no puedo entender.

Amutuy, Soledad, que mi hermano me arrincona, sin piedad vámonos que el hambre $\mathrm{y}$ el fiscal

pueden más, Amutuy, sin mendigar.

Amutuy, Amutuy, Amutuy sin mendigar."

(Amutuy-soledad. Letra: Marcel Berbel ${ }^{7}$ ).

\footnotetext{
${ }^{6}$ Refere-se à marca comercial de armas de fogo.

${ }^{7}$ Letra da canção, interpretada por Soledad Pastorutti, disponível em http://letras.mus.br/soledadpastorutti/747885/ Acesso: 14 mar. 2016.
} 
Num nível primeiro de análise, a palavra "атиtuy" presente no título, conforme o dicionário online da $\mathrm{RAE}^{8}$, não existe na língua espanhola. Buscamos respostas para o que significaria, e, segundo Duarte e Gonzalez (2012), trata-se de um vocábulo na língua Mapuche ${ }^{9}$ que, em espanhol, seria "vamos" ou "vámonos", em alguns contextos.

No título, a palavra "soledad" significa, literalmente, "solidão", mas, segundo o dicionário da RAE, pode significar também "lugar desierto o tierra no habitada". Conforme Duarte e Gonzalez (2012), a ambiência que gerou a canção foi o momento de comemoração dos 500 anos da chegada dos europeus à América. O ponto central das festividades era exaltar o avanço dos estados nacionais sobre os povos remanescentes. Segundo o site Memória Chilena $^{10}$, o povo Mapuche - um dos primeiros agrupamentos americanos - já habitavam os pampas argentinos e chilenos desde os tempos da chegada dos europeus. O autor da letra, Marcel Berbel, era filho de pai espanhol e mãe mapuche, e passou sua vida na província de Neuquén, Argentina (região pampeana).

Há como pano de fundo da canção um cenário histórico muito peculiar em que se inscrevem e sobrepõe-se pelo menos três tempos: primeiro, o território latino-americano sendo conquistado ou invadido pelos europeus; segundo, a chamada "Campanha do deserto": as necessidades econômicas levaram o estado a uma espécie de demarcação de fronteiras interiores, por volta do século XIX. Dentre elas, as regiões da Patagônia e do Chaco habitadas pelas populações indígenas que resistiam aos avanços da sociedade nacional foram os alvos primeiros. O avanço territorial foi feito pelos exércitos, e as cenas de crueldade contra os nativos se multiplicaram. No entanto, os índios resistiram. E um terceiro, as comemorações dos 500 anos de descoberta/invasão.

Conforme o site Memória Chilena, o povo Mapuche, desde seus primórdios, tem como característica fundamental demarcar o seu lugar no espaço e nas lutas por fronteiras com os espanhóis, no início da colonização e, depois do período colonial, com os chilenos. Dado esse contexto, temos que aceitar que há uma relação com um mito fundacional, como explica Hall (2001, p. 55): “uma estória que localiza a origem da nação, do povo e de seu caráter nacional num passado tão distante que eles se perdem nas brumas do tempo, não do tempo 'real', mas de um tempo 'mítico"”. E é a esse tempo mítico que recorre o enunciador da canção, e a ele que nos remetemos para dialogar com a obra de arte.

\footnotetext{
${ }^{8}$ Real Academia Española, instituição de referência para esta língua. http://www.rae.es/. Em todos os casos em que for necessária a tradução, será utilizado como parâmetro este site.

${ }^{9}$ De um dos povos originários da região do chaco argentino.

${ }^{10}$ Disponível em http://www.memoriachilena.cl/602/w3-article-781.html\#presentacion Acesso: 14 mar. 2016.
} 
Na canção, há um herói atemporal, que é o índio, que de uma forma ou de outra, tornou-se vítima de um conquistador, nos princípios, pela imposição de uma língua, de uma crença e de uma cultura diferentes; depois, o índio é "arrinconado" pelo próprio "hermano", ou seja, é posto em um lugar retirado do que era seu pelos próprios irmãos, argentinos expulsando argentinos, porque eram indígenas e, sendo expulsos, de cabeça baixa saem, pois a fome e o fiscal podem mais; e, por último, o momento em que os de "sable" e "cruz", os exércitos e os religiosos, fazem uma festa para comemorar o seu poder, e o índio que habita a "periferia do poder" (RAMA, 2015), não é convidado e, assim, não entende o motivo da celebração.

\section{Considerações finais}

Cada um é bárbaro do outro; basta, para sê-lo, falar uma língua que esse outro ignora: para ele será apenas um burburinho.

Tzvetan TODOROV

Como arremate ao artigo, parece-nos que a questão primeira foi alcançada: descobrir qual(is) o(s) motivo(s) do discurso identitário da canção "Amutuy, soledad”. Como sugerem os estudos bakhtinianos, não se constitui a identidade sem a alteridade, visto que o "eu" e "outro" são os centros de valor que dispõem todos os momentos concretos do existir. O tratamento da canção como obra de arte, como sugerido por Voloshinov/Bakhtin (1976), permitiu-nos analisá-la de maneira participante, isto é, entendê-la como uma parte do processo de compreensão que depende tanto de suas características materiais, do autor e das atitudes do contemplador. Devemos concordar com Canclini (2008), pois, se nos globalizarmos, abriremos espaço(s) para o(s) outro(s) que, por definição, desmantelaria a identidade.

Como conclusão ao(s) motivo(s) do discurso de identidade, além daquelas que figuram na subseção anterior, podemos nos apropriar da definição de "comunidades guardaroupa” de Bauman (2005), nas quais, invocadas apenas pelas aparências, penduram-se os problemas individuais por algum tempo em nome de um evento particular que ocorre, e, tão pronto o espetáculo se desfaz, arruína-se a comunidade. O discurso identitário presente ali é datado na medida em que se refere às comemorações dos 500 anos da presença estrangeira na América Latina, por isso uma comunidade guarda-roupa.

A questão do grande tempo é bastante pertinente para pensarmos no discurso veiculado pela canção. As teorias sobre identidade, tanto Bauman (2005) quanto Hall (2011), 
apontam-nos que os grupos identitários estão desmantelados. Podemos afirmar que, na contemporaneidade, vivemos para o "outro", não mais para o "eu". O discurso da canção quebra com esse postulado justamente porque busca no tempo grande a identidade constituída na diferença durante os 500 anos de "descoberta" ou "invasão" da América. O outro que não fora convidado vem, invade e domina. Esse outro, com força, impõe o seu dizer, a sua lógica de mundo. Mas a constituição de alteridade que vem dessa relação é da ordem do humanismo da identidade, nos termos de Dias (2015); é o humanismo que impõe as maneiras de pensar, que se fecha para a escuta, é um outro impositivo e não aberto à alteridade. É o outro da lógica colonizadora. Esse outro que é constituidor de uma identidade assim tão fechada, assim tão sem ar, sem liberdade.

Por fim, os resultados da discussão apontam para a permanência, no grande tempo, dos mitos fundacionais, que não desaparecem sem deixar vestígios. Eles voltam a aparecer, simultaneamente, em épocas diferentes. Entretanto, os mitos não surgem apenas recontados, mas carregados de sentidos outros, porque respondem aos anseios de diferentes sujeitos.

\section{Referências}

BAKHTIN, M. M. Estética da criação verbal. Tradução do russo de Paulo Bezerra. São Paulo: Martins Fontes, 2011. BAKHTIN, M. M. Marxismo e filosofia da linguagem. Tradução de M. Lahud e Yara Vieira. São Paulo: Ed. Hucitec, 2009.

BAKHTIN, M. M. No tempo grande. In: BOUKHARAEVA, L. M. Começando o diálogo com Mikhailovitch Bakhtin. Ijuí: Ed. Unijuí, 1997.

BRANDÃO, C. O que é folclore? São Paulo: Brasiliense, 1984.

BAUMAN, Z. Identidade. Entrevista a Benedeto Vechi. Tradução Carlos Alberto Medeiros. Rio de Janeiro: Jorge Zahar Ed., 2005.

BAUMAN, Z. Modernidade líquida. Tradução Plínio Dentzien. Rio de Janeiro: Jorge Zahar, 2001.

CANCLINI, N. La globalización imaginada. Buenos Aires: Paidós, 2008.

CHILENA, Memória. El Pueblo mapuche. Disponível em http://www.memoriachilena.cl/602/w3-article-781.html\#presentacion . Acesso em 25 de outubro de 2018.

CHULLIVER, R. Folklore. Buenos Aires: Centro de estudios folklóricos, 2012.

DIAS, A. B. F. A amorosidade entre humanismo da identidade e humanismo da alteridade: alguns desafios no fazer científico. In: Grupos Atos e outros. III EEBA - Encontro de 
Estudos Bakhtinianos - Amorização: porque falar de amor é um ato revolucionário. São Carlos: Pedro \& João Editores, 2015.

DUARTE, G. R.; GONZALEZ, E. Visões sobre a conquista da América hispânica pela música popular. In: Texto e argumento - Revista do programa de pós-graduação em história. Florianópolis: v.4 n. 2, 2012.

GERALDI, J. W. A diferença identifica. A desigualdade deforma. Percursos bakhtinianos de construção ética e estética. In: FREITAS, M. T. (Org.). Ciências humanas e pesquisa. São Paulo: Cortez, 2003.

GERALDI, J. W. Ancoragens - Estudos bakhtinianos. São Paulo: Pedro \& João Editores, 2015.

GINZBURG, C. Sinais: raízes de um paradigma indiciário. In: GINZBURG, Carlo. Mitos, emblemas, sinais, morfologia e história. São Paulo: Companhia das letras, 1989.

GIOVANI, F.; SOUZA, N.B. Lugar da filosofia - heterociência nas ciências humanas: cotejando textos - convite para caminhada metodológica. In: GIOVANI, F.; SOUZA, N. B. Bakhtin e a educação: a ética, a estética e a cognição. São Carlos : Pedro \& João Editores, 2014.

HALL, S. A identidade cultural na pós-modernidade. Tradução de Tomaz Tadeu da Silva e Guaracira Lopes Louro. Rio Janeiro: DP\&A, 2011.

MELLO, M. B.; MIOTELLO, V. Questões bakhtinianas para uma heterociência humana. In: Revista Teias. V. 14. N.31. Culturas, linguagens e a pesquisa em educação, 2013.

MIOTELLO, V.; MOURA, M. I. de. Apresentação - alargando os limites da identidade. In: Grupo de estudos dos gêneros do discurso GEGe/UFSCAR (orgs.). A escuta como lugar do diálogo - alargando os limites da identidade. São Carlos: Pedro \& João Editores, 2012.

PONZIO, A. A revolução bakhtiniana: o pensamento de Bakhtin e a ideologia contemporânea. Coordenação de tradução de Valdemir Miotello. São Paulo: Contexto, 2012. RAMA, A. A cidade letrada. Tradução de Emir Sader. São Paulo: Boitempo, 2015.

SAUSSURE, F. Curso de linguística geral. Tradução de Antônio Chelini, José Paulo Paes, Izidoro Blikstein. São Paulo: Cultrix, 2012.

SANTOS, B.S. Para além do pensamento abissal: das linhas globais a uma ecología dos saberes. In. SANTOS, B.S. MENESES, M.P. (orgs.) Epistemologias do sul. Coimbra: Edições Almedina, 2009.

SOUZA, N. B. A construção contraditória do discurso identitário no cancioneiro de Soledad Pastorutti no contexto do folclore argentino. Dissertação (Mestrado em linguística). Pós-Graduação em Linguística da Universidade Federal de São Carlos (UFSCar). São Carlos: Brasil, 2017. 
SOUZA, N.B. Poética, mas solitária e triste: a América Latina na vida e na poesia - metáforas do caminhar como utopia. In: GRUPO DE ESTUDOS DOS GENEROS DO DISCURSO GEGe. (Org.). V CÍRCULO Rodas de Conversa bakhtiniana: praça pública, multidão, revolução, utopia. 1ed. São Carlos: Pedro \& João Editores, 2014.

SOUZA, N.B. Uma leitura da heterociência/ciência outra de Bakhtin: quando a cientificidade não cabe nos tubos de ensaio. In: Grupo de Estudos dos Gêneros do Discurso - GEGeUFSCar. (Org.). Palavras e contrapalavras: lendo pedaços singulares do mundo com Bakhtin. 1ed.São Carlos: Pedro \& João Editores, 2016, v. 1, p. 219-230.

TODOROV, T. A conquista da América - a questão do outro. Tradução de Beatriz Perroni Moisés. São Paulo: Martins Fontes, 2010.

VOLOSHINOV, V. N.; BAKHTIN, M. M. Discourse in life and discourse in art: concerning sociological poetics. Tradução para fins didáticos de Carlos Alberto Faraco e Cristovão Tezza. New York: Academic Press, 1976. 